\title{
An Investigation of Offender and Victim Relationships in a Sample of Juvenile Homicides in California
}

\author{
G. Solomon Osho \\ Prairie View A \& M University \\ Fay Williams \\ Northern Caribbean University
}

Accepted: Jan 17, 2013 Published: Feb 25, 2013

Doi:10.5296/jsr.v4i1.3005 URL: http://dx.doi.org/10.5296/jsr.v4i1.3005

\begin{abstract}
Homicide is the one of the most heinous crime however in most cases it is related to social interaction between people. Disaggregating the homicide data based on victim-offender relationship can provide additional information that would otherwise have been overlooked. This study seeks to determine the relationship between the selected situational and socio-demographic variables and the victim-offender relationship among the juvenile homicides. The situational and demographic variables that were statistically significant in the Chi Square test were also significant in the logistic regression model using acquaintance homicide as the dependent variable. This research revealed that among the demographic variables- gender, marital status, education and race were all statistically significant. Routine activity theory provided an excellent framework for understanding crime but also for implementation and intervention strategies for different types of homicide.
\end{abstract}

Keywords: Victim offender relationship, socio-demographic, homicide, juvenile,

\section{Introduction}

Homicide is the one of the most heinous crime however; it can be useful by more accurately reflecting crime levels within a community. Historically, homicides were viewed as a homogenous group and studies focused on characteristics of the victim, the state of the society or other behavioral factors such as drug use or gang involvement that may have contributed to the deadly act. However, one of the first suggestions to categorize homicide by the relationship between the victim and offender was proposed by Marvin Wolfgang, 1958 . From his classic study, "Patterns in Criminal Homicide", he found that homicides occurred most frequently among people who were related or associated with each other such as relatives and friends. He therefore suggested that homicides should not be treated as a homogeneous group and that attempts to disaggregate homicide would provide additional 
information. He also suggested that stranger homicide would be less between people who knew each other such as friends and acquaintances. This research proposes to fill the gap in the literature by answering the following questions: (1) Is there a significant relationship between the situational variables and the victim- offender relationship among the juvenile homicides? (2) Is there a significant relationship between the socio-demographic variables and the victim offender relationship among the juvenile homicides? (3) What are the homicide characteristics of the different victim-offender relationships?

\section{Relevant Prior Research}

Schultz (1966) suggested that obtaining information on the victim and offender was important for intervention because victims are sometimes engaged in behaviors that may trigger their victimization. He therefore suggested that the additional information could be used within the court system in order to facilitate court decisions, sentencing and the elucidation of court cases. Homicide involving strangers tend to take longer to be cleared as compared to homicide among persons who have been related or who know each other.

Although investigation of the cultural, sociological and personal factors associated with homicide are important, nevertheless they do not fully explain all types of homicide. Investigating the victim-offender relationship by disaggregating the homicide data revealed another perspective that would be helpful to policy makers, criminologist, law enforcement and the public in general. Carach 1997 said that the dynamic aspect of homicide may be better understood by analyzing victims and offenders. He reported that males are more likely to perpetrate homicide $(90 \%)$ and that acquaintance homicide tends to occur more frequently at a rate of $1 / 3$ and stranger homicide at $1 / 6$. He also stated that youth violence tend to occur among unrelated persons.

Disaggregating the homicide data based on victim-offender relationship has several benefits. First, it will highlight correlates of a homicide that has previously being overlooked. It provides increased information that can be used as a basis for intervention and prevention strategies thereby reducing the likelihood that these fatalities will occur. Additionally, it can be useful within the court system in facilitating court decision such as sentencing and case clearance through elucidation of the crime. Watkins \& Decker (2007) stated that investigating victim-offender relationship in homicides is significant in determining how quickly the cases are cleared. He also suggested that homicides involving strangers tend to take longer to be cleared than those involving family members or intimates.

Several victim-offender typologies have been suggested. Decker (1993) initially proposed a five category classification of the victim-offender relationship including strangers, acquaintances, friends, romantic links and relatives because he thought that the more precise the relationship, the more detailed information would be obtained. However since some of the classification was subjective he adopted the three category classification in 1996 . He then grouped friends with romantic links and relatives as one group; with stranger and 
acquaintance as the other two groups. He reported that there are higher rates of gun usage among friend and family homicides compared to stranger homicide. He suggested that having outdoors as the crime premises reduced the probability of killing between acquaintances/friend and family homicides.

Cao, Hou \& Huang, 2008 conducted his study in Taiwan using a three group classification scheme. They grouped friends and acquaintances together, romantic links and relatives as another and then strangers. His findings demonstrate that $48 \%$ of the suspects were involved in acquaintance or friend homicide, $20 \%$ intimate while $32 \%$ had stranger homicide. He noted that a weapon was more frequently used among acquaintance/friend homicide rather than among stranger or intimate homicide. In their, study, a knife was the weapon of choice in $67 \%$ of the cases. The crime premises for friend/acquaintance and intimate were more likely to occur within a building compared to stranger homicide that occurred outside in a public place. They concluded that there was no statistical significance between education, gender, gun as weapon, and time of crime and homicide.

Drawdy \& Myers, 2004 examined victim \& offender relationship by classifying the homicides into two groups. One group was identified as a primary relationship including intimates, relatives, and friends while the second group had secondary relationship including acquaintances and strangers. They found no correlation between weapon used and the victim/offender relationship.

\section{Theoretical Framework}

Although victim-offender relationship can provide increased understanding of homicides it is nevertheless important to identify the context within which the incident occurs. Routine activity theory provides a theoretical framework that supports the situational context of homicides. It is one of the main theories of "environmental criminology. This perspective was advanced by Larry Cohen \& Marcus Felson, 1979) who took a practical and pragmatic look at crime. They reported that in order for a crime to occur, there are 3 elements that must be present namely a suitable target, lack of a competent guardian and a motivated offender (Williams \& McShane, 2004). This theory facilitates the development of intervention strategies such as police intervention, target hardening through environmental and development of education programs.

The purposes of this study are to identify the association between the victim-offender relationship and the situational and demographic variables among juvenile homicides. The study was initially inspired based on a report from Taiwan by Cao, Hou \& Huang who suggested that further studies from the United States could provide a comparison for cross-national research. This study will contribute to the body of knowledge on victim-offender relationship because although Wolfgang suggested this approach since 1958, there are only few studies that have explored the relationship. It will also seek to demonstrate the applicability of the routine activity theory to victim-offender relationships particularly as 
it relates to prevention and crime control for stranger homicides.

The three category classification used by Cao, Hou \& Huang 2008 was adopted for this study where family/intimate homicide included individuals who may be romantically involved or who are relatives such as a parent and child relationship. Acquaintance/friend homicide referred to the relationship where persons know and are familiar or aware of each other prior to the incident while in stranger homicide there is no previous association or exposure between the offender and the victim (Cao, Hou \& Haung, 2008).

\section{Methods}

Data. This study investigated the offender-victim relationship among juvenile homicides using secondary data obtained from California. The data was collected from a linked homicide file that was developed by the California Department of Health Services, Epidemiology and Prevention for Injury Control Branch and the Supplementary Homicide reports obtained from the Department of Justice. This database linked the supplementary homicide report with the California Department of Health Services vital statistics and mortality data. The total data set consisted of 34,542 records of homicides for the period 1990-1999.

Sample Selection. The sample was selected by identifying the age group 10-17 years and then eliminating the records in a systematic manner in order to avoid using entries with missing data (Table 1). As a result, statistical analysis will only be done on cases that contain all the variables being investigated. The final sample consisted of 1,406 homicides with youth's ages 10 to 17 years.

\section{Table 1: Selection of Sample}

\begin{tabular}{lll}
\hline Population of homicide & & 34,542 \\
Selection of youths 10-17 & $-32,141$ & 2401 \\
Omit 'other as cause of death & -114 & 2287 \\
Delete no weapon & -20 & 2284 \\
Delete no premises & -17 & 2267 \\
Delete education unknown & -142 & 2125 \\
Delete no time of incident & -719 & 1406 \\
Final Sample & & 1406 \\
\hline
\end{tabular}

Sample characteristics. The dependent variable is the victim-offender relationship which is broken down into three subgroups namely stranger, friends and acquaintance and partner and family (Cao, Hou \& Haung, 2008). The independent variables include both situational and demographic variables that were extracted from the data. The situational variables include total number of offenders, the weapon used, and the location and time of incident. The demographic variables include age, sex, race of victim and marital status and educational 
level of the suspect.

Statistical Analysis. Statistical analysis was done by using SPSS 15.0. Descriptive statistics was used to measure of central tendency including frequency distribution and the chi square test. After the descriptive statistics was completed, the variables were then recoded into binary in order to facilitate logistic regression analysis. Age as a continuous variable was recoded into $10-13$ years $=0$ and 14-17 $=1$. Victim-offender relationship was recoded into acquaintance $=1$ and other relationship $=0$. Race/ethnicity was coded as black $=1$ and other races $=0$. The highest level of education obtained was recoded as high school and college $=1$ and elementary and middle school $=0$. The weapon was coded as gun $=1$ with knife and no weapon $=0$. Statistical significance was observed at the .05 level.

\section{Findings}

The age range of the suspects was 10-17 years with a mean of 16 years and a standard deviation of 1.19 (Table 1). The distribution was highly skewed to the right with only 4\% (58) of respondents in the 10-13 age group while the 15-17 year old accounted for $96 \%(1,246)$ of the sample.

Table 2: Descriptive Statistics of Sample $(n=1406)$

Variable

\section{Demographic}

Age (Mean)

Victim's Education

Elementary

Middle

High

College

Gender $($ male $=1)$

Marital status(married=1)

Ethnicity -

Hispanic

White

Black
$\mathrm{N}$

1406

165

178

1022

41

1367

219

450

108

848

855

50

1215

141

571
$\%$

16 years

72.7

2.9

97.2

15.6

7.7

60.3

Situational

Crime Premises (Outside=1)

60.8

Weapon

No sharp Weapon

Gun

86.4

Knife

10.0

Time of day (Day=7am-6pm)

Dependent Variable 


\begin{tabular}{cll}
\hline Acquaintance & 847 & 60.2 \\
Family & 79 & 5.6 \\
Stranger & 480 & 34.1 \\
\hline *p-value<.05 **p-value<.01 & $* * *$ p-value<.001 &
\end{tabular}

*p-value<.05 **p-value<.01 *** p-value $<.001$

Acquaintance homicide accounted for the larger proportion of cases $60 \%$ (847) while stranger homicide was just over half of the acquaintance group. Family homicide accounted for only $6 \%$ (79). As with most crime data, males were predominantly involved representing $97.2 \%$. The ethnic groups were disproportionately represented in the sample of with $60.3 \%$ blacks and $32 \%$ Hispanics with Whites being represented by only $8 \%$. Using a database from California is ideal because it is one of the most ethnically diverse states but nevertheless having the largest population of white Americans.

The majority of the homicides $60.4 \%$ occurred during the night between 6 p.m. and 7 a.m. This was surprising because it would have been expected that juveniles would have being more involved in crime and other negative behaviors during the daylight hours. The gun was the weapon of choice accounting for $86.4 \%$. This finding is similar to those from adult homicide, however bearing in mind that the youths are between 10- 17 years, the gun would have been illegal or was obtained from their parents. Cao, Hou \& Huang, 2008 in a similar study reported that a weapon was more frequently used among acquaintance/friend homicide rather than among stranger or intimate homicide. They identified the knife as the weapon of choice in $67 \%$ of the cases. Two variables of the victim was also investigated, they include education level and marital status. The findings show that the majority of the victim had either a high school education $(72.7 \%$ ) with $24 \%$ not having a high school education. The majority of the victims were single with only $15.6 \%$ being married.

Table 3: Cross tabulation of Variables based on Victim-offender Relationship

\begin{tabular}{lllll}
\hline & \multicolumn{2}{l}{ Victim-Offender Relationship } & & \\
& Stranger & Acquaintance & Chi Square & \\
Variable & $\%$ & $\mathrm{~N}$ & $\%$ & Sig \\
Age & 15 & 43 & & \\
$(1=14-17)$ & 883 & 1348 & 21.84 & .175 \\
Education & 155 & 188 & & \\
$1=$ H/school/ college & 325 & 738 & $24.64^{*}$ & .000 \\
Gender & 4 & 35 & & \\
1=Male & 476 & 891 & $10.18^{*}$ & .001 \\
Marital status & 363 & 824 & & \\
1=Married & 117 & 102 & $42.91^{*}$ & .000 \\
Ethnicity - & 304 & 652 & & \\
(black=1) & 274 & 956 & $7.28^{*}$ & .007 \\
Crime Premises & 161 & 390 & & \\
\hline
\end{tabular}




\begin{tabular}{lcccc}
\hline (1=Outside $)$ & 319 & 536 & $9.75 *$ & .002 \\
Weapon & 69 & 122 & & \\
$(1=$ gun $)$ & 411 & 804 & .388 & .53 \\
Time of day & 301 & 534 & & \\
$(1=$ daylight $)$ & 179 & 392 & 3.33 & .068 \\
\hline *p-value<.05 & $* *$ p-value<.01 & $* * *$ p-value<.001 & &
\end{tabular}

The Chi square was used to determine if there is a significant relationship between victim-offender relationship and the situational and demographic variables (Table 2). Among the situational variables, crime premises (9.75) was the only statistically significant variable while gender (10.18), marital status, (42.91), education (24.64) and race (7.28) were all statistically significant among the demographic variables. Cao, Hou \& Huang, 2008 in his study concluded that there was no statistical significance between education, gender, gun as weapon, and time of crime and homicide. All the variables that were statistically significant in the Chi Square test at the .05 level were put into the logistic regression model with acquaintance homicide as the dependent variable (Table 4).

Table 4: Model 1: Logistic Regression with outcome as Acquaintance Homicide

\begin{tabular}{|c|c|c|c|c|c|c|}
\hline & \multicolumn{6}{|c|}{$95 \% \mathrm{CI}$ for $\mathrm{Ex}(\mathrm{B})$} \\
\hline & B & S.E. & Wald & $\operatorname{Exp}(B)$ & Lower & Upper \\
\hline Crime Premises & -.465 & .124 & 14.113 & .621 & .488 & .792 \\
\hline Suspect Gender & 1.670 & .549 & 9.267 & .189 & .065 & .549 \\
\hline Suspect Race & -.394 & .126 & 9.823 & .694 & .545 & .885 \\
\hline Victim's Education & .642 & .135 & 22.709 & 1.868 & 1.438 & 2.427 \\
\hline V/Marital Status & -.943 & .156 & 36.312 & .385 & .284 & .523 \\
\hline Constant & 2.562 & .626 & 16.731 & 11.058 & & \\
\hline
\end{tabular}

The Odds Ratio for crime premises (.621) being outside reduced the likelihood of acquaintance homicide thus providing a protective effect against that type of violence.

The odds ratio for gender (.189) being male considerably reduced the likelihood of acquaintance homicide thus providing a protective effect against that type of violence.

The odds ratio for race (.694) being black reduced the likelihood of acquaintance homicide thus providing a protective effect against that type of violence.

The odds ratio for victim's education (1.868) increased the likelihood of acquaintance homicide thus providing a victimizing effect towards acquaintance violence.

The odds ratio for marital status (.385) being married reduced the likelihood of acquaintance 
homicide thus providing a protective effect against that type of violence.

Stranger Relationship. Based on the results of the statistical analysis, it can be deduced that crime premises (outside) could increase the likelihood of stranger homicide. Regarding gender and ethnicity being male and black would increase the likelihood of stranger violence. The victim not having a high school education would reduce the likelihood of acquaintance homicide and increase the likelihood of stranger crime. The odds ratio for victim's education (1.868) increased the likelihood of acquaintance homicide thus providing a victimizing effect towards acquaintance violence. The odds ratio for marital status (.385) being married increase the likelihood of stranger homicide.

Acquaintance Relationship. Crime premises as outside, being male, being black and married reduced the likelihood of acquaintance homicide thus provided a protective effect against that type of violence. With victim's education being high school or above (1.868) increased the likelihood of acquaintance homicide thus providing a victimizing effect towards acquaintance violence.

One limitation of the study is that the use of secondary data prevented access to variables that could provide pertinent information such as criminal history, drug use and premeditation. It was surprising to recognize that the majority of the homicides committed by the juveniles occurred at night with the use a gun. Gun was the most weapon of choice accounting for 86.4\% when compared with Cao, Hou \& Huang 2008 where a knife was the most popular weapon. Based on the age of the youths the question arises where they get the guns, these weapons are illegal or were obtained from parents.

Among the situational variables, the chi square identified crime premises; time of day and the weapon used were not statistically significant. The chi-square also revealed that among the demographic variables: gender, marital status, education and race were all statistically significant at the .05 level. Crime premises, being black, gender and victim's marital status reduced the likelihood of acquaintance homicide thus providing a protective effect against that type of violence however victim's education increased the likelihood of acquaintance homicide thus providing a victimizing effect towards acquaintance violence.

\section{Discussion and Recommendations}

The authorities need to reinvest once again in schools and their after school program to protect our youth from a life of crime. Promote dispute resolution programs to reduce interpersonal conflicts

Law enforcement to be involved with patrolling hot spots

Involve volunteers from faith-based groups and other types of community organization.

Provide support for families especially those with risk factors and facilitate parenting training 
Provide mentoring or similar programs to help at-risk youths remain in school and out of crime. Collaborate with the media personnel to reduce the glamorization of crime and violence and gun use and promote wholesome healthy programming and balanced reporting of crime news. Enforce and reinforce gun safety measures because the youths appear to have ready and easy access to a weapon.

Based on routine activity theory people should attempt to reduce the likelihood of becoming a vulnerable target by developing awareness of criminal possibilities in the surroundings and the likelihood for an incident occurring because of the dynamic nature of the guardian, victim and offender interaction. The Theory also provides an excellent framework for understanding crime but also for implementation on intervention strategies. In keeping with the findings that most homicide occurs outside of a building, then steps for target hardening could be employed. These would include identifying hot spots, increasing police and security presence, provision of competent guardian in parking lots and other open spaces through improved lighting, security cameras, guards, neighborhood watch schemes, having vigilant staff and co-workers, close circuit television systems. These measures would also be recommended to impact on stranger homicide because the majority of them occur outside of buildings.

The investigation of victim-offender relationship provided additional information that would have been overlooked when cultural and social disorganization factors are investigated. Since a wide range of factors may contribute to homicide, more extensive study is necessary to provide a more comprehensive explanation by simultaneously investigating different approaches or theoretical framework to determine constituent proportions of different theories for each homicide type.

\section{References}

Cao, L., Hou, C. \& Huang, B.( 2008). Correlates of the Victim-Offender

Relationship in Homicide. International Journal of

Offender Therapy and Comparative Criminology, 52(6) 658-672

Carach, C. (1997).Youth as victims and offenders of Homicide. Australian Institute of Criminology, 1-19

Decker, S. H. (1993). Exploring victim-offender relationships in homicide: The role of individual and event characteristics. Justice Quarterly, 10, 585-612.

Decker, S. H. (1996). Deviant Homicide: A New Look at the Role of Motives and VictimOffender Relationships Journal of Research in Crime and Delinquency, Vol. 33, No. 4 , 427-449

Koons-Wit, B. A \& Schram, P. J. (2006). Race Does Race Matter? Examining the Relationship Between Co-Offending and Victim Characteristics for Violent Incidents 
Involving Female Offenders. Feminist Criminology, 1(2), 125-146

Lusignan, R. \& Marleau, J. D. (2007). Risk assessment and Offender-Victim relationship, in juvenile offenders. International journal of offender therapy and comparative Criminology, 51(4) 433-443

Kaukinen, C. (2002) The help-seeking decisions of violent crime victims: An Examination of the direct and conditional effects of gender and the Victim-Offender relationship. Journal of interpersonal violence, 17( 4), 432-456

Kubrin, C. E., (2003). Structural covariates of homicide rates: does type of homicide matter? Journal of research in crime and delinquency, 40 (2), 139170

Piquero, A. R. \& Brame, R. W. (2008). Assessing the Race-Crime and Ethnicity-Crime relationship in a Sample of Serious Adolescent Delinquents. Journal of Research in Crime and delinquency, Vol. 45, No. 3, 227-255

Salfati, C. G. (2003). Offender Interaction with victims in homicide. Journal of Interpersonal Violence, 18 (5), 490-512

Ullman, S. E., Filipas, H. H, Townsend, S. M. \& Starzynski, L. L. (2006). The Role of Victim- Offender Relationship in Women's Sexual Assault Experiences. Journal of Interpersonal Violence, 21

Williams, F. P. \& McShane, M. D. (2004). Criminology Theory $4^{\text {th }}$ Ed. Upper Saddle River Pearson Prentice Hall, 237-243

Wolfgang, M. (1958). Patterns in criminal homicide. Philadelphia: University of Pennsylvania Press. 